\title{
A comparative study of Pap smear and colposcopy guided biopsy in the evaluation of unhealthy cervix
}

\author{
Meenakshi Venkatesh*, Ushadevi Gopalan
}

Department of Obstetrics and Gynecology, Shri Sathya Sai Medical College and Research Institute, Tamil Nadu, India

Received: 26 March 2020

Accepted: 29 April 2020

\section{*Correspondence:}

Dr. Meenakshi Venkatesh,

E-mail: meenakshisevu@gmail.com

Copyright: (c) the author(s), publisher and licensee Medip Academy. This is an open-access article distributed under the terms of the Creative Commons Attribution Non-Commercial License, which permits unrestricted non-commercial use, distribution, and reproduction in any medium, provided the original work is properly cited.

\begin{abstract}
Background: Cancer of cervix ranks as the third common malignancy in females worldwide. In developing countries like India, carcinoma cervix is the second commonest malignancy affecting females. In India, every year 1,26,000 new cases are identified and 67,477 deaths occur due to cervical carcinoma. Cervical carcinoma affects women of age 15-44 years and disease peaks at 55-66 years. On average, Indian women have a $2.5 \%$ risk of developing carcinoma cervix. It was estimated worldwide that every $5^{\text {th }}$ woman, who suffer from cervical cancer belongs to India.

Methods: A comparative study which included 110 married women of age 20 to 65 years. Women who presented with white discharge, lower abdominal pain, post coital bleeding and post-menopausal bleeding were subjected to Pap smear and colposcopy guided biopsy.

Results: A total $53.6 \%$ women had inflammatory smear, followed by $34.5 \%$ women with normal Pap smear, $0.1 \%$ women had bacterial vaginosis, 6.4\% women had LSIL and 4.5\% women had HSIL. Authors found that $63.6 \%$ women had chronic cervicitis. $15.4 \%$ had chronic endo papillary cervicitis, $13.6 \%$ had CIN 1, 5.4\% women had CIN 2 and $1.8 \%$ women had squamous cell carcinoma. Association of Pap smear with histopathology is statistically significant ( $\mathrm{p}$ value $<0.001$ ).

Conclusions: Pap smear can be used as screening test for detecting premalignant lesions of cervix. Colposcopy guided cervix biopsy has got better specificity than Pap smear, so all symptomatic women should be subjected to colposcopy guided cervix biopsy to detect carcinoma at early stage.
\end{abstract}

Keywords: Cervical carcinoma, Colposcopy guided biopsy, Pap smear

\section{INTRODUCTION}

Cancer of cervix ranks as the third common malignancy in females worldwide. ${ }^{1}$ In developing countries like India, carcinoma cervix is the second commonest malignancy affecting females. India accounts for $18 \%$ of the global burden of carcinoma cervix. ${ }^{2}$

In India, every year 1,26,000 new cases are identified and 67,477 deaths occur due to cervical carcinoma. ${ }^{3}$ Cervical carcinoma affects women of age 15-44 years and disease peaks at 55-66 years. On average, Indian women have a $2.5 \%$ risk of developing carcinoma cervix. ${ }^{4}$ It was estimated worldwide that every $5^{\text {th }}$ woman, who suffer from cervical cancer belongs to India. ${ }^{5}$

According to WHO, $80 \%$ of death from carcinoma cervix is from developing countries. In India, carcinoma cervix plays a major role in mortality and morbidity of patient. ${ }^{6}$ In developing countries like India, more than $70 \%$ of the population lives in rural areas. Rural Indian women undergo early marriage, multiple childbirth, poor nutrition status and they lack awareness about contraception, availability of screening programmes and therefore are prone to acquire carcinoma cervix. ${ }^{7}$ According to a survey conducted by NFHS -2, only $50 \%$ 
of rural women are exposed to newspaper and television. Until rural women develop awareness about screening programs, it is very difficult to prevent carcinoma cervix. $^{2}$

Cervical cancer is a malignancy that has got a long latent period to transform into invasive carcinoma, so if women undergo screening at an early stage of disease, invasive lesion of cervix can be prevented. ${ }^{8}$ More than $80 \%$ of women with cervical carcinoma present with advanced stage of disease, due to their lack of health education, awareness of screening programs and lack of accessibility to medical services. ${ }^{9}$ The most common type of carcinoma of cervix is squamous cell carcinoma. Nowadays, adenocarcinoma is on the rise due to increased use of oral contraceptives. Most common cause of cervical carcinoma is human papillomavirus (HPV). Subtypes HPV-16 and HPV-18 are involved in almost $99 \%$ of invasive lesion of carcinoma cervix. ${ }^{10}$

Cervix is easy for accessibility. Cervical epithelial cells have got potential to change to dysplasia and invasive carcinoma. Premalignant lesions of cervix had got long latent period. Hence, women should undergo screening regularly to detect premalignant lesions of the cervix. ${ }^{3}$

Papanicolaou (Pap) smear is a simple, cheap and noninvasive method used for screening of carcinoma cervix, with specificity of $94 \%$ and sensitivity of $72 \% .^{11}$

\section{METHODS}

Married women aged 20-65 years attending gynecology OPD of Shri Sathya Sai Medical College and Research Institute, a tertiary care hospital in Kancheepuram district, Ammapettai in Tamil Nadu South India. This was 18 months study. Quasi experimental study conducted at Shri Sathya Sai Medical College and Research Institute, a tertiary care hospital, Ammapettai in Tamil Nadu, South India.

\section{Inclusion criteria}

- Married women between ages of 20-65 year's

- Women with symptoms like vaginal discharge, postcoital bleeding, post-menopausal bleeding, persistent leucorrhoea.

\section{Exclusion criteria}

- Unmarried women

- Pregnant women

- Women with frank lesion and active infection

- Women below age of 20 years and women above 65 years.

Sample size was calculated based on the study by Kalyankar et al. ${ }^{1}$
$\mathrm{P}-80 \%$

$\mathrm{Q}-100-80=20$

Formula used in determining sample size is $\mathrm{N}-4 \mathrm{PQ} /(\mathrm{L})^{2}$, where $\mathrm{P}$ is prevalence is $80 \%$

$\mathrm{Q}$ is $100-\mathrm{P}=20$

$\mathrm{L}$ is $10 \%$ error of prevalence

$\mathrm{L}=4 \times 80 \times 20 /(8)^{2}$

$=6400 / 64=100$

( $10 \%$ non-response error is $10 \%)$

$=100+10$

$=110$

\section{Methodology}

A total 110 patients satisfying inclusion criteria will be included in the study of age group 20-65 years. An Informed written consent shall be taken from all the subjects. Detailed history regarding age, age at marriage, age at first pregnancy, parity, menstrual history, presenting symptoms will be asked. Through speculum examination, Pap smear will be taken. Using colposcopy, colposcopy guided biopsy will be taken. Staining will be done with universal stain for cytological preparations. Papanicolaou stain is Harris haematoxylin the optimum nuclear stain and combination of OG6 and EA 50. Bethesda classification will be used for reporting.

Colposcopy on a rolling stand was used with a focal length of $300 \mathrm{~nm}$. It is a microscope which consist of the binocular head with eye piece the main objective, microscope tilt, and illuminating system with built in filters. Green filter serves to enhance the fine details of vascular pattern of the target epithelium. The light source on colposcope is halogen. Colposcopic signs were scored under Reid colposcopic index in following categories:

- Sharpness of margin

- Epithelial colour

- Vascular pattern

- Iodine staining.

Each category was given three points.

$\begin{array}{ll}\text { Scores } & \text { Diagnosis } \\ 0-2 & \text { CIN 1 } \\ 3-4 & \text { CIN 1 -CIN 2 } \\ 5-8 & \text { CIN2-CIN3 }\end{array}$

\section{Statistical analysis}

Data was entered into Microsoft excel and SPSS (Statistical package for social science) version 23.0 was used for descriptive statistics. Categorical data was analysed using percentage. Inferential statistics was analysed using Chi-square test. The probability value of $<0.05$ was considered as statistically significant. 


\section{RESULTS}

In this study, $42.7 \%$ women belong to age group $31-40$ years. $30.9 \%$ women belong to $41-50$ years of age. $14.5 \%$ women belong to 20-30 years of age, $9.1 \%$ women belong to 51-60 years of age and $2.7 \%$ women are more than 60 years of age. In this study $38.2 \%$ women were para $3,33.6 \%$ women were para $4,15.5 \%$ women were para $5,6.45$ women were para $2,4.5 \%$ women were para 6 and $1.8 \%$ women were primipara.

In this study population, white discharge was the most common chief complaint $(46.4 \%)$, followed by lower abdominal pain in $24.5 \%$, low back ache in $10.9 \%$, postcoital bleeding in $10 \%$ and postmenopausal bleeding seen in $8.2 \%$. Majority of women $(63.6 \%)$ had their first child before 20 years of age, $30 \%$ women had their first child between 21-30 years and 6.4\% women had their first child between 31-40 years of age.

In this study, $53.6 \%$ women had inflammatory smear, followed by $34.5 \%$ women with normal Pap smear, $0.1 \%$ women had bacterial vaginosis, $6.4 \%$ women had LSIL and $4.5 \%$ women had HSIL. In this study, authors found that $63.6 \%$ women had chronic cervicitis. $15.4 \%$ had chronic endo papillary cervicitis, $13.6 \%$ had CIN $1,5.4 \%$ women had CIN 2 and $1.8 \%$ women had squamous cell carcinoma. In this study, association of Pap smear with histopathology is statistically significant ( $\mathrm{p}$ value $<0.001$ ) (Table 1).

Table 1: Comparison of Pap smear with percentage of histopathology results.

\begin{tabular}{|c|c|c|c|c|c|c|c|c|c|c|c|c|}
\hline \multirow{3}{*}{ Pap smear } & \multicolumn{10}{|c|}{ Histopathology } & \multicolumn{2}{|c|}{ Chi square } \\
\hline & \multicolumn{2}{|c|}{$\begin{array}{l}\text { Chronic } \\
\text { cervicitis }\end{array}$} & \multicolumn{2}{|c|}{$\begin{array}{l}\text { Chronic endo } \\
\text { papillary cervicitis }\end{array}$} & \multicolumn{2}{|c|}{ CIN I } & \multicolumn{2}{|c|}{ CIN II } & \multicolumn{2}{|c|}{ SCC } & \multirow[t]{2}{*}{$\begin{array}{l}\text { p- } \\
\text { value }\end{array}$} & \multirow[t]{2}{*}{ Result } \\
\hline & No. & $\%$ & No. & $\%$ & No. & $\%$ & No. & $\%$ & No. & $\%$ & & \\
\hline $\begin{array}{l}\text { Negative for } \\
\text { intraepithelial } \\
\text { malignancy }\end{array}$ & 35 & $50 \%$ & 3 & $17.6 \%$ & 0 & $0 \%$ & 0 & $0 \%$ & 0 & $0 \%$ & & \\
\hline Inflammatory smear & 33 & $47.1 \%$ & 14 & $82.3 \%$ & 10 & $66.8 \%$ & 2 & $33.3 \%$ & 0 & $0 \%$ & $<0.001$ & Significant \\
\hline Bacterial vaginosis & 1 & $1.4 \%$ & 0 & $0 \%$ & 0 & $0 \%$ & 0 & $0 \%$ & 0 & $0 \%$ & & \\
\hline LSIL & 1 & $1.4 \%$ & 0 & $0 \%$ & 4 & $26.8 \%$ & 2 & $33.3 \%$ & 0 & $0 \%$ & & \\
\hline HSIL & 0 & $0 \%$ & 0 & $0 \%$ & 1 & $6.8 \%$ & 2 & $33.3 \%$ & 2 & $100 \%$ & & \\
\hline
\end{tabular}

\section{DISCUSSION}

This study included 110 women in which $42.7 \%$ women belonged to age group 31-40 years, which is comparable to the study by Kalyankar et al $(39.7 \%)$, Shaki et al $(44.4 \%)$ and Thobbi VA et al $(35 \%) .^{1,3,6}$ In the studies done by Vincent et al and Sathiyakala et al, $26.5 \%$ women and $20 \%$ women belonged to the same age group, respectively. ${ }^{4,8}$ The findings in their studies could be different from the present study because their study sample was more compared to this study.

In this study, $22.72 \%$ of women in the age group of 31-40 years had inflammatory Pap smear. In the age groups, 3140 years, 41-50 years and 51-60 years, LSIL was found in $1.8 \%$ of women in each age group.

In the age groups, 41-50 years and 51-60 years, HSIL was seen in $1.8 \%$ of women in each age group. Also, $1.8 \%$ ( 2 women) had squamous cell carcinoma in this study. In these two women, one belonged to the age group 41-50 years and another woman belonged to the age group 51-60 years. Both these women were multiparous, had early marriage and belonged to low socio-economic class. Thus, these two women had multiple high-risk factors for developing carcinoma cervix.
In this study, $88.25 \%$ of women were from rural areas, $11.08 \%$ were from urban areas, whereas in studies done by Narayana et al $77.9 \%$ women belonged to rural population. $^{12}$

In this study, $38.2 \%$ of women were multiparous, which is comparable to the study by Kalyankar et al in which, $38.2 \%$ women were multiparous. ${ }^{1}$ In contrast, in studies done by Shaki et al, Arya et al and Parveen et al 16.4\%, $78 \%$ and $23 \%$ of women were multiparous, respectively. $6,13,14$

In this study, white discharge was the most common complaint $(46.4 \%)$, followed by lower abdominal pain $(24.5 \%)$, postcoital bleeding $(10 \%)$ and post-menopausal bleeding $(8.2 \%)$, which is similar to the study by Kalyankar et al and Garg et al. ${ }^{1,2}$ In another study done by Shaki et al, white discharge was seen in $36.5 \%$, postcoital bleeding in $3 \%$ and postmenopausal bleeding in 5\%. ${ }^{6}$ Similarly, in a study by Sachan et al, white discharge was seen in $36.96 \%$, abdominal pain in $25.6 \%$, postcoital bleeding in $3.09 \%$ and postmenopausal bleeding in $1.45 \% .{ }^{15}$ Vincent et al observed that white discharge was seen in $30.21 \%$, abdominal pain in $17.73 \%$ and post-menopausal bleeding in $1.25 \%$ whereas Manjit et al observed bleeding per vaginum in $79.1 \%$, white discharge in $8.3 \%$ and abdominal pain in $4.1 \%$. $^{4,16}$ These 
variations could be due to differences in ethnicity and study population.

In this study, 2 women (1.8\%) had carcinoma cervix. They were multiparous women, belonging to low socioeconomic group. Among them, one woman presented with post coital bleeding and other women presented with postmenopausal bleeding. These are the most common symptoms of carcinoma cervix.

In this study, on per speculum examination, $29.1 \%$ of women had white discharge, followed by cervical erosion in $19.1 \%$, hypertrophied cervix in $18.2 \%$, congested cervix in $14.5 \%$, cervical erosion that bleeds on touch in $11.8 \%$ and cervix with foul smelling discharge that bleeds on touch in $7.3 \%$ women. These findings were different from the study by Shaki et al, in which white discharge was seen in 56\%, cervical erosion in $15.55 \%$, cervix that bleeds on touch in $2 \%{ }^{6}$

A study by Kalyankar et al, found cervical erosion in $30.61 \%$, ectropion in $14.28 \%$, congested cervix in $6.12 \%$ and leukoplakia in $1.02 \%{ }^{1}$ In another study done by Saleh et al, they found ectropion in $36 \%$, cervicitis in $18.90 \%$, hypertrophied cervix in $14.90 \%$, cervix that bleeds on touch in $14.90 \% .{ }^{17}$ These differences could be due to variation in observers, interpretation errors and large sample size.

In this study, on Pap smear examination, authors found that $34.5 \%$ had normal Pap smear, 53.6\% had inflammatory Pap smear, $0.1 \%$ had bacterial vaginosis, $6.4 \%$ had LSIL and $4.5 \%$ had HSIL, while in a study by Vincent et al, 22.15\% had normal Pap smear, $75.47 \%$ had inflammatory Pap smear, $58.90 \%$ had bacterial vaginosis, $65.85 \%$ had LSIL, and $26.83 \%$ had HSIL. ${ }^{4}$ These differences may be due to differences in study population, observer errors, and also due to the fact that in this study, most of the women belonged to low socio economic class and hence, are more prone to infection and develop carcinoma cervix.

In this study, in the age group of 31-40 years, $22.72 \%$ of women had inflammatory Pap smear, whereas in each of the age groups of 31-40 years, 41-50 years and 51-60 years, LSIL was seen $1.8 \%$. In the age group of $41-50$ years, HSIL was seen in $1.8 \%$ of women. In contrast to this study, Vincent et al found that $44.44 \%$ had LSIL in the age group of 50-59 years and $36.36 \%$ had HSIL in the age group of 40-49 years. ${ }^{4}$ In a study by Thobbi et al, $33.7 \%$ and $57.9 \%$ of women belonging to $35-39$ years had inflammatory smears and LSIL respectively, and $1.5 \%$ of women belonging to $40-45$ years had HSIL. ${ }^{3}$

Sachan et al, found that $48.8 \%$ of women had normal smear, $42.6 \%$ had inflammatory smear, $5.09 \%$ had LSIL and $0.48 \%$ had HSIL. ${ }^{15}$ These findings in the studies are different, which could be due to variation in observers and differences in interpretation of results. Also, these variations may be due to the larger sample size in their study.

\section{ACKNOWLEDGMENTS}

Authors would like to thank dean, Dr. Sukumaran Annamalai, Shri Sathya Sai Medical College and Research Institute, Kancheepuram district, for granting me permission to carry out this study. Authors would also thanks to take this opportunity to convey my heartiest gratitude and sincere thanks to Co-guide Dr. Dost Mohammed Khan, MD professor and HOD, department of pathology, Shri Sathya Sai Medical College and Research Institute, who with their vast knowledge and professional expertise have provided with guidance and constant encouragement throughout the course of this study and in the preparation of this dissertation. Authors extend their sincere gratitude to Dr. K. Sivankumar, professor and HOD of obstetrics and gynecology.

Funding: No funding sources

Conflict of interest: None declared

Ethical approval: The study was approved by the Institutional Ethics Committee

\section{REFERENCES}

1. Kalyankar VY, Kalyankar BV, Gadappa SN, Kute S. Colposcopic evaluation of unhealthy cervix and it's correlation with Papanicolau smear in cervical cancer screening. Int J Reprod Contracept Obstet Gynecol. 2017;6:4959-65.

2. Garg R, Desai R. Cytologic and colposcopic evaluation of all symptomatic women at tertiary care centre. Int J Adv Med. 2017;4:799-80.

3. Thobbi VA, Khan F. Cervical cytology by Pap smear in reproductive population. Int $\mathrm{J}$ Reprod Contracept Obstet Gynecol. 2018;7:1988-92.

4. Vincent M. Pap smear as a screening tool for evaluating cervical dysplasia and malignancy a hospital-based study. J Evolution Med Dent Sci. 2019;8(17):1368-71.

5. Sharma JC, Leekha K. Awareness, positivity of Pap smear in adult females. Indian J Gynecol Oncol. 2018;16(3):46.

6. Shaki O, Chakrabarty BK, Nagaraja N. A study on cervical cancer screening in asymptomatic women using Papanicolaou smear in a tertiary care hospital in an urban area of Mumbai, India. J Fam Med Prim Care. 2018;7(4):652.

7. Sinha S, Singh V, Mishra B, Singh A. Comparing the efficacy of visual inspection of cervix with acetic acid and Lugol's iodine with Pap smear cytology in screening for cancer cervix. J Cur Res Scient Med. 2018;4(1):10.

8. Rajendiran S, Gopalan U, Karnaboopathy R. Evaluation of histopathology of cervix in women with unhealthy cervix. Int $\mathbf{J}$ Reprod Contracept Obstet Gynecol. 2017;6(3):842-5. 
9. Vidyadhar DS, Bhattacharya DA, Bohara DS, Dwivedi DA, Agarwal DA, Gangwar DD. Comparison and correlation of cytology, colposcopy and histopathology of premalignant lesions of cervix in rural women of Barabanki district. IOSR J Dent Med Sci. 2017;16(04):13-8.

10. Thumoju S, Divyakolu S, Bhopal T, Gowrishetty S, Fatima SS, Ahuja YR, et al. Experiences from cervical cancer screening program conducted at lowresource areas in Telangana. Int J Med Public Health. 2018;8(3):112-5.

11. Das D, Kar A, Rath S, Baliarsingh SK, Prusty D, Dash AK. Cytological pattern of papanicolaou smears and detection of cervical cancers: An experience from a tertiary care center of eastern zone of India. Oncol J India. 2018;2(2):25.

12. Narayana G, Suchitra MJ, Sunanda G, Ramaiah JD, Kumar BP, Veerabhadrappa KV. Knowledge, attitude, and practice toward cervical cancer among women attending obstetrics and gynecology department: a cross-sectional, hospital-based survey in South India. Indian J Cancer. 2017;54(2):481.

13. Arya R, Arora R, Benwal D, Kumar VK, Verma S. Can visual inspection after acetic acid replace papanicolaou smear. J Evidence-Based Women's Health J Soci. 2015;5(1):38.
14. Parvin Z, Naher L, Das SK, Khanam S, Rosy N. Visual inspection of cervix with acetic acid (VIA) as a screening tool for early detection of cervical precancer and cancer. Faridpur Med Coll J. 2018;13(1):24-7.

15. Sachan PL, Singh M, Patel ML, Sachan R. A study on cervical cancer screening using pap smear test and clinical correlation. Asia-Pacific J Oncol Nurs. 2018;5(3):337.

16. Rana MK, Singh K, Mahajan MK, Rana AP. Clinicopathological profile of cervical carcinoma: An experience of tertiary care cancer centre. Asian Pacific J Cancer Care. 2019;4(3):83-6.

17. Saleh HS, El Hameid AA, Mowafy HE, Sherif HE, Abdelsalam WA. Visual inspection of the cervix with (acetic acid or lugol's iodine) for cervical cancer screening. Gynecol Obstet (Sunnyvale). 2016;6:111.

Cite this article as: Venkatesh M, Gopalan U. A comparative study of Pap smear and colposcopy guided biopsy in the evaluation of unhealthy cervix. Int J Reprod Contracept Obstet Gynecol 2020;9:2305-9. 